\title{
Thrombosis of the portal venous system
}

\author{
D. Sacerdoti*, G. Serianni, S. Gaiani, M. Bolognesi, \\ G. Bombonato, A. Gatta
}

Department of Clinical and Experimental Medicine, Clinica Medica 5, University of Padova, Italy

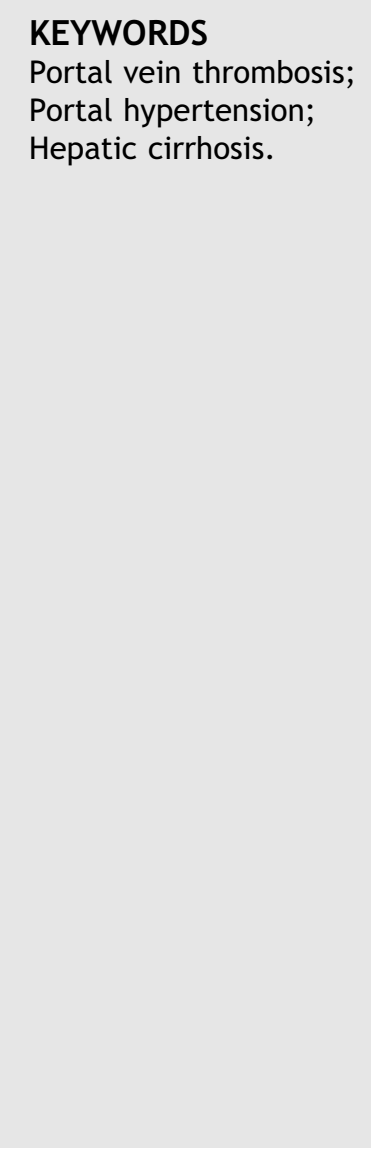

\begin{abstract}
Portal vein thrombosis (PVT) is a rare cause of portal hypertension. Its diagnosis has been facilitated by improvements in imaging techniques, in particular Doppler sonography. The prevalence is about $1 \%$ in the general population, but much higher rates are observed in patients with hepatic cirrhosis $(7 \%$, range $0.6-17 \%)$, particularly those who also have hepatocellular carcinoma (HCC) (35\%). The most common causes of PVT are myeloproliferative disorders, deficiencies of anticoagulant proteins, prothrombotic gene mutations, cirrhosis with portal hypertension, and HCC. Its development often requires the presence of two or more risk factors (local and/or systemic), e.g., a genetically determined thrombophilic state plus an infectious episode or abdominal surgery. It is clinically useful to distinguish between cirrhotic and noncirrhotic forms. Portal vein thrombosis is also traditionally classified as acute or chronic, but this distinction is often difficult. Color Doppler ultrasound is the first-line imaging study for diagnosis of PVT; magnetic resonance angiography and CT angiography are valid alternatives. The main complications are ischemic intestinal necrosis (in acute PVT) and esophageal varices (in chronic cases); the natural history of the latter differs depending on whether or not the thrombosis is associated with cirrhosis. The treatment of choice for PVT has never been adequately investigated. It is currently based on the use of anticoagulants associated, in some cases, with thrombolytics, but experience with the latter agents is too limited to draw any definite conclusions. In chronic thrombosis (even forms associated with cirrhosis), anticoagulant therapy is recommended and possibly, beta-blockers as well. Naturally, treatment of the underlying pathology is essential.
\end{abstract}

Sommario La trombosi portale rappresenta una causa rara di ipertensione portale che oggi viene diagnosticata con maggior facilità per l'affinamento delle metodiche di imaging, in particolare quelle ecografiche. La prevalenza è dell' $1 \%$ circa, del $7 \%(0,6-17 \%)$ nella cirrosi epatica, del $35 \%$ circa nell'epatocarcinoma. Le cause più comuni di trombosi portale sono: i disordini mieloproliferativi, il deficit di proteine anticoagulanti, le mutazioni geniche protrombotiche, la cirrosi con ipertensione portale, l'epatocarcinoma. Per lo sviluppo di trombosi portale è spesso necessaria la presenza di due o più fattori, locali e sistemici, come uno stato trombofilico su base genetica e un episodio infettivo o un intervento chirurgico addominale. $\grave{E}$ utile clinicamente dividere la trombosi portale in cirrotica e non-cirrotica. La trombosi portale

\footnotetext{
* Corresponding author. Dipartimento di Medicina Clinica e Sperimentale, Clinica Medica 5, via Giustiniani 2, 35100 Padova, Italy. E-mail address: david.sacerdoti@unipd.it (D. Sacerdoti).
} 
è inoltre tradizionalmente classificata in acuta e cronica, ma spesso è difficile distinguerle. L'indagine di primo livello per la diagnosi di trombosi portale è rappresentata dall'ecocolor-Doppler; in alternativa possono essere usate angio-RM e angio-TC. Le conseguenze della trombosi portale sono rappresentate principalmente dalla necrosi intestinale ischemica nelle forme acute e dalle varici esofagee, che hanno una storia naturale diversa a seconda della presenza o meno di cirrosi, nelle forme croniche. Non vi sono studi adeguati sulla terapia della trombosi portale, che attualmente consiste nell'anticoagulazione, a cui può essere associata la trombolisi, sulla quale non vi è però casistica adeguata. Nella trombosi cronica è indicata l'anticoagulazione, probabilmente anche nella cirrosi, ed eventualmente il beta-bloccante. Ovviamente importante è la terapia della patologia di base.

(c) 2007 Elsevier Masson. All rights reserved.

\section{Introduction}

The portal venous system, which consists in the mesenteric, splenic, and portal veins, is peculiar in that its communication with the systemic circulation is not direct but mediated by the hepatic sinusoids. Occlusion of a portal vessel causes congestion of the organs it drains, with increased venous pressures and the development of collateral circulation. It can also reduce hepatic perfusion by as much as $2 / 3$, but these downstream effects are much less evident (particularly in noncirrhotic forms), and they have yet to be fully characterized. Adequate blood flow to the liver is maintained thanks to the so-called arterial "buffer" response [1] (i.e., compensatory dilatation of the hepatic artery) and the development of collateral porto-portal pathways, including cavernomas. The principle is similar to that of a surgical porto-caval shunt although the pressures are much higher. The clinical picture varies depending on the extension of the thrombosis, how rapidly it develops, and the presence or absence of cirrhosis. The picture is different when the thrombosis is limited to one of the portal branches. This situation leads to atrophy of the lobe affected by the thrombosis and hypertrophy of the contralateral lobe, an effect that is exploited during surgical resection of HCC in a cirrhotic liver [2].

Reported prevalence rates for PVT vary widely due to the diverse and often nonspecific symptoms, which complicate diagnosis. In a recently reported autopsy series (close to 24,000 cases representing $84 \%$ of all hospital deaths occurring between 1970 and 1982) [3], the overall prevalence of PVT was $1.1 \%$. Higher rates were observed among patients with myeloproliferative diseases $(3 \%)$ or hepatic cirrhosis (6\%), particularly those with HCC (14.3\% vs. $4.5 \%$ among cirrhotic patients without HCC). Most cases were thus associated with primary hepatic tumors (prevalence rates of $5.7 \%$ among noncirrhotic patients and $14.3 \%$ of those with cirrhosis) or liver metastases (prevalence 3.3\%).

In the last ten years, substantial improvements have been made in noninvasive imaging methods such as Doppler ultrasound, computed tomography (CT), or magnetic resonance imaging (MRI), and it is now much easier to obtain precise information on the abdominal vessels and their flow characteristics. As a result, PVT is being diagnosed with increasing frequency, and our understanding of this condition is evolving rapidly. Important advances have also been made in the field of hereditary and acquired coagulation disorders, shedding new light on the potential causes of venous thrombosis.
In this paper, we analyze our own experience with patients with cirrhotic and noncirrhotic forms of PVT in light of the most recent advances that have been made in this field.

\section{Etiology}

Thrombosis of the portal vein system is often the result of multiple factors. The factors implicated this far (Table 1) include prothrombotic disorders (hereditary or acquired), other thrombophilic factors, and local factors.

Tab. 1 Factors causing portal vein thrombosis

Tab. 1 Fattori responsabili di trombosi del sistema portale

Common Uncommon

Hereditary prothrombotic risk factors

Mutation of the factor

Antithrombin III deficit

$\checkmark$ Leiden gene

Mutation of the factor Protein C deficit

II [G20210] gene

Mutation of the MTHF Protein S deficit

reductase gene

Acquired prothrombotic risk factors

Use of oral contraceptives Myeloproliferative

Pregnancy and post-partum

diseases

syndrome

Inflammatory states Paroxysmal nocturnal

Malignancies hemoglobinuria

Hyperhomocysteinemia

Inflammatory lesions

Lesions involving the portal vein system

Local risk factors

Neonatal omphalitis

Diverticulitis

Appendicitis

Pancreatitis

Duodenal ulcer

Cholecystitis

Tubercular lymphadenitis

Cirrhosis

Tumors in the abdominal cavity 


\section{Thrombosis of the portal venous system in patients without cirrhosis}

In $40-70 \%$ of noncirrhotic patients with PVT, one or more thrombophilic factors, hereditary or acquired, can be identified; local causes can be documented in $10-40 \%$, and in $20 \%$, there is no identifiable cause $[4,5]$.

\section{Hereditary thrombophilias}

The hereditary disorders can be divided into two categories based on their frequencies. The more common forms (with estimated prevalence rates of $>2 \%$ in the general population) are due to mutation of the genes encoding factor $\mathrm{V}$ Leiden, factor II G20210, or methylenetetrahydrofolate reductase (MTHFR). They confer a relatively limited risk for thrombosis (relative risk $=2-8$ ). Protein $C$, protein $S$, and antithrombin III (AT-III) deficits are less common (estimated prevalence: $<4 \%$ ), but these conditions are associated with a considerably higher thrombogenic risk (relative risk: $\sim 10$ ).

A mutation of factor $\mathrm{V}$ Leiden that renders it resistant to neutralization by activated protein $C$ [6] is more common in patients with thrombosis of the hepatic veins ( $25 \%)$ [7] or those of the lower limbs [5]: it is found in approximately $5 \%$ of all cases of PVT [8]. Mutation at position 20210 in the prothrombin gene is associated with high plasma levels of prothrombin, and its prevalence seems to be increased among subjects with hepatic or portal vein thrombosis, compared with controls [4]. Homozygous C $>$ T mutation at position 677 (C677T) of the MTHFR gene is associated with high plasma levels of homocysteine and an increased risk of venous thrombosis [9], but it has recently been shown that the prevalence of C677T homozygosity among patients with PVT is no higher than that observed in healthy European populations ( $\sim 10 \%)$ [4]. As for deficits in protein $\mathrm{C}$, protein S, or AT-III, the prevalence of these anomalies in general Caucasian populations is low $(<4 \%)$, but even heterozygous forms carry a high risk for thrombosis (relative risk: $\sim 10$ ). Protein $C$ deficits have been found in approximately $10-30 \%$ of patients with noncirrhotic PVT while lower rates have been reported for protein S or AT-III deficits (4-5\%) [9-12]. One group, however, found protein $\mathrm{S}$ deficits in $30 \%$ of the patients they examined, but none had protein $C$ deficits [4]. It is often difficult to establish the primary nature of alterations of this sort since a number of conditions can cause secondary reductions in the plasma levels of these factors, including disseminated intravascular coagulation, infections, and, in particular, various types of liver failure.

\section{Acquired prothrombotic factors}

The acquired risk factors for thrombosis also include common and less common conditions. The latter subgroup includes myeloproliferative diseases, the antiphospholipid antibody syndrome, and paroxysmal nocturnal hemoglobinuria. The more common risk factors are the use of estrogen-progestin contraceptives, pregnancy, post-partum, inflammatory states, neoplastic disease, and hyperhomocysteinemia. The prothrombotic risks associated with neoplastic disease are well known, particularly the myeloproliferative forms, which cause $30-40 \%$ of all cases of PVT and $50 \%$ of those involving the hepatic veins $[4,13,14]$. As for the antiphospholipid antibody syndrome, approximately $1 / 5$ patients with thrombosis of the hepatic veins and $1 / 10$ of those with PVT are positive for these antibodies [4].

\section{Local factors}

Local factors can be divided into three categories. The first includes local inflammatory changes (neonatal omphalitis, diverticulitis, appendicitis, pancreatitis, duodenal ulcer, cholecystitis, tubercular lymphadenitis, chronic inflammatory bowel diseases). The second includes factors related to local manipulation during surgical procedures. The most frequent is undoubtedly splenectomy, which is also associated with reduced portal blood flow. The third group is made up of abdominal tumors that compress and/or invade the portal vessels. In most of these situations, two or more mechanisms are usually operating. In inflammatory or septic states, Bacteroides bacteremia has been shown to be associated with thrombosis of the portal and mesenteric veins [15]. The incidence of PVT in patients with ulcerative colitis varies widely from $1.3 \%$ [16] to $39 \%$ (in an autopsy series) [17]. Splenoportal thrombosis is found in $13 \%$ of all patients with chronic pancreatitis, and it is generally due to vessel compression by pseudocysts or to acute pancreatitis [18]. Portal vein thrombosis is a rare complication of liver transplantation: the incidence is $2.0 \%$ in recipients of cadaver organs (the risk is especially high in children) and $0.5-2.0 \%$ in those receiving live-donor livers.

\section{Thrombosis of the portal venous system in patients with cirrhosis}

Among patients with cirrhosis, the reported prevalence of portal vein thrombosis ranges from $2 \%$ to $26 \%$ [19]. Figures vary widely depending on how long ago the study was conducted. In our experience, for example, when diagnoses were based on angiographic findings, we found a prevalence of $3.8 \%$ (among the 420 patients studied). Today, this rate is much higher due to our routine use of color Doppler sonography: $6.6 \%$ of 1500 cirrhotic patients studied [20]. Among patients who are on transplant waiting lists (and therefore have advanced disease), the prevalence of PVT is $8.4 \%$, and the incidence is $7.4 \%$ [19]. Blood stasis caused by portal hypertension is considered to be the most important pathogenic mechanism, but this has never actually been demonstrated, and other factors (local, hereditary and/or acquired thrombophilic factors) are equally important. Treatment of portal hypertension with beta-blockers, which causes additional decreases in portal flow rates, does not appear to increase the risk for PVT.

\section{Hereditary disorders}

Conflicting findings have been published regarding the role of genetic mutations in the pathogenesis of cirrhotic PVT. One group has reported an increased frequency of factor $V$ Leiden mutations in patients with cirrhosis and PVT compared with cirrhotics who do not have thrombosis and those with thrombosis in healthy livers [21]; other investigators, however, have found no difference between these groups [22]. In one study, the $20210 \mathrm{G}-\mathrm{A}$ mutation of the prothrombin gene was found to be significantly more common among cirrhotic patients with PVT. It was the only independent risk factor identified and increased the risk for 
thrombosis fivefold [23], but, again, these findings have not been confirmed by other researchers [22]. It is difficult to evaluate anti-thrombotic protein deficits (proteins $C$ and $\mathrm{S}, \mathrm{AT}$-III) in patients with cirrhosis due to their reduced hepatic synthesis. However, similar levels have been reported in cirrhotic patients with and without PVT, suggesting that these alterations probably do not play a fundamental role in the pathogenesis of cirrhotic PVT [21]. Hepatic cirrhosis is also one of the causes of acquired hyperhomocysteinemia, but this does not seem to be associated with an increased risk of portal thrombosis [23]. Antibodies against cardiolipin are also fairly common in patients with cirrhosis, but they seem to represent an epiphenomenon of the liver damage [23].

\section{Acquired prothrombotic factors}

In patients with advanced cirrhosis who are awaiting liver transplants, the only factors found to be independent predictors of portal vein thrombosis were quite nonspecific, i.e., a low platelet count and a history of bleeding varices. Platelet counts seem to be inversely related to the risk of thrombosis [20]. As for acquired coagulation abnormalities, patients with advanced cirrhosis and portal vein thrombosis have significantly decreased levels $(-40 \%)$ of factor VIII, probably as a result of its consumption during the thrombotic process. In contrast, in cirrhosis without PVT factor VIII levels are increased, probably due to extrahepatic production, anomalies in the protein itself, or its reduced catabolism [24]. Hyperfibrinolysis with elevated D-dimer levels has also been described in hepatic cirrhosis. It is caused by primary activation of the coagulation system, delayed hepatic clearance of tissue plasminogen activator, and reduced hepatic synthesis of fibrinolysis inhibitors. D-dimer levels are markedly increased in patients with more severe forms of cirrhosis and even higher in the presence of portal vein thrombosis. In advanced cirrhosis, D-dimer and factor VIII levels can be used only for ruling out the presence of portal vein thrombosis [24].

\section{Local factors}

Sclerotherapy and abdominal surgery are the only local factors found to be independent predictors of PVT; liver failure is not an independent predictor [22].

\section{Clinical manifestations}

\section{Noncirrhotic portal vein thrombosis}

Portal vein thrombosis may be completely asymptomatic and diagnosed by chance. It can also be associated with nonspecific symptoms like abdominal pain and/or splenomegaly or severe manifestations like gastrointestinal hemorrhage [25] caused by esophageal varices or hemorrhagic intestinal infarction. Rapid onset PVT may be associated with transient ascites or in rare cases hepatic encephalopathy accompanied by gastrointestinal hemorrhage, transient ileus, abdominal tension, diarrhea, nausea, or thrombophlebitic splenomegaly of Eppinger-Frugoni. In the past 20 years, improvements in noninvasive diagnostic imaging techniques (Doppler, CT, etc.) have changed the clinical history of patients with thrombosis of the splenoportal axis, and abdominal pain is now the most common presenting symptom. Cases of PVT heralded by gastrointestinal bleeding are much less common (2.4/100 cases/year vs. 12.7/ 100 /year) since this phenomenon is much more evident in the latter stages of the disease. Compared with cirrhotic forms, noncirrhotic PVT is less likely to be associated with esophageal varices, and when it is, the varices are generally less severe and the risk of bleeding is about $1 / 3$ lower; the six-year risk of death from variceal bleeding is $14 \%$ [26].

The impact on the intestinal circulation depends on whether the thrombus extends to the superior mesenteric vein and mesenteric venous arcades: as long as these vessels remain patent, they can provide collateral circulation. When the mesenteric arcades are obstructed, reflex arteriolar vasoconstriction may occur. Persistence of the ischemia for several days can lead to a picture of intestinal infarction, which is responsible for $20-50 \%$ of the deaths related to PVT (even if the ischemic segment is resected). Small intestine stenosis can also be a late complication of mesenteric venous ischemia.

In patients with chronic PVT and portal cavernomas, abnormalities are sometimes observed in the extrahepatic biliary tree. They can be caused by compression of the bile ducts by the cavernoma itself, choledochal or periportal varices, or post-ischemic pericholedochal fibrosis. In rare cases, jaundice, cholangitis, or cholecystitis develop when the cavernoma involves the wall of the gall bladder. Biliarytract hemorrhage may also be seen as a result of the rupture of choledochal varices [27].

In patients with inflammatory bowel disease, PVT can be suspected during work-up for an acute exacerbation of the intestinal disease. The thrombosis is often asymptomatic (PVT is found at autopsy in around $40 \%$ of all patients with inflammatory bowel disease) [17], or it may be manifested by bleeding esophageal varices. In patients with these diseases, sonography should be performed to rule out the presence of PVT. If thrombosis is present, prompt treatment with colectomy can produce substantial benefits, including recanalization of the obstructed vein [28]. Portal hypertension secondary to noncirrhotic PVT can also be associated with a hyperdynamic syndrome like that seen in cirrhosis, with increases in blood volume and cardiac output [29].

\section{Cirrhotic portal vein thrombosis}

In patients with cirrhosis, PVT can be asymptomatic (43\%). Symptomatic forms may be associated with the onset or worsening of ascites, bleeding varices, portal hypertensive gastropathy $(39 \%)$, or intestinal infarction $(13 \%)$. Thrombus formation is generally a slow process that allows time for the development of collateral circulation. In the presence of high portal pressures, however, even partial or segmental obstruction of the portal system can lead to variceal bleeding. Approximately half of all patients with complete occlusion of the main portal vein are symptomatic. However, there is no correlation between the extension of the portal thrombosis and the risk of gastrointestinal bleeding [23]. Compared with varices of the same caliber in a noncirrhotic patient with PVT, those found in cirrhotic patients bleed more frequently [30], and the mortality rates associated with these hemorrhages are substantially higher. This 
observation suggests that the main risk factor in these patients is the severity of the liver disease, which determines the prognosis.

If the thrombus extends into the superior mesenteric vein, symptoms almost inevitably develop due to the absence of efficient mesenteric collaterals. In these cases, the patient generally presents with signs and symptoms of intestinal ischemia [23].

\section{Diagnosis}

In the past, thrombosis of the portal vessels was diagnosed with angiography or splenoportography. Today, the vessels of the splanchnic district can be accurately explored with noninvasive diagnostic methods like ultrasound or color Doppler ultrasound. The sonographic diagnosis of portal vein thrombosis is based on demonstration of echogenic material (Fig. 1) that obstructs the lumen of the vessel and the complete or partial absence of flow in the portal vein or on the presence of collateral circuits that by-pass the obstructed vessel, the most typical form being the cavernoma (Fig. 2), a tangle of tortuous vessels, irregular in caliber, that includes the vasa vasorum of the portal vein and the pericholecystic vessels. If the obstruction is partial, color Doppler can reveal areas of the lumen that are patent and/or the presence of some flow downstream from the thrombus (Fig. 3); the complete absence of flow should be confirmed with pulsed Doppler (Fig. 4).

There are various systems for sonographic classification of PVT. Nonami [31] distinguishes four grades: grade 1 thrombosis involves the intrahepatic portal branches, grade 2 involves the right or left portal vein or the bifurcation, grade 3 refers to partial thrombosis of the main portal vein, and grade 4 is applied to thrombi that completely obstruct the lumen of the main branch of the portal vein. Jamieson [32] divides thromboses of the spleno-mesentericoportal axis into (1) partial or complete thrombosis that is limited to a segment of the portal vein distal to the splenomesenteric confluence; (2) thrombosis that extends into the proximal superior mesenteric venous system; (3) diffuse thrombosis of the splanchnic venous system with largecaliber collaterals; (4) diffuse thrombosis of the splanchnic venous system with small-caliber collaterals.

Doppler sonography (ideally associated with color and power Doppler) is highly sensitive and specific, and it represents the first-line study for suspected portal vein thrombosis. The sensitivity of color Doppler sonography is considered similar to that of CT [33]. In some cases (e.g., when large collateral circuits have formed), Doppler studies are more accurate than arteriography [34]. The main limitations of the sonographic approach are its poor visualization of the splanchnic vessels, quality that is highly operator-dependent, and difficulties caused by the presence of large hepatic masses or lobar hypertrophy, anatomic changes, and/or pneumobilia. Despite its high sensitivity, in some patients ( $9 \%$ according to Marshall [35]) color-Doppler sonography is difficult to perform well, and the patency of the portal vein cannot be verified with certainty. In these cases, the use of a sonographic contrast agent substantially improves visualization [35].

In patients with neoplastic disease, color Doppler sonography and angio-CT have proved to be equally effective for the diagnosis of PVT. Using intraoperative findings as the gold standard, the two methods were similar in terms of sensitivity (93\% vs. $90 \%)$, specificity ( $99 \%$ for both), positive and negative predictive values ( $97 \%$ vs. $95 \%$ and $98 \%$ vs. $97 \%$, respectively) [36]. During the first seven days following

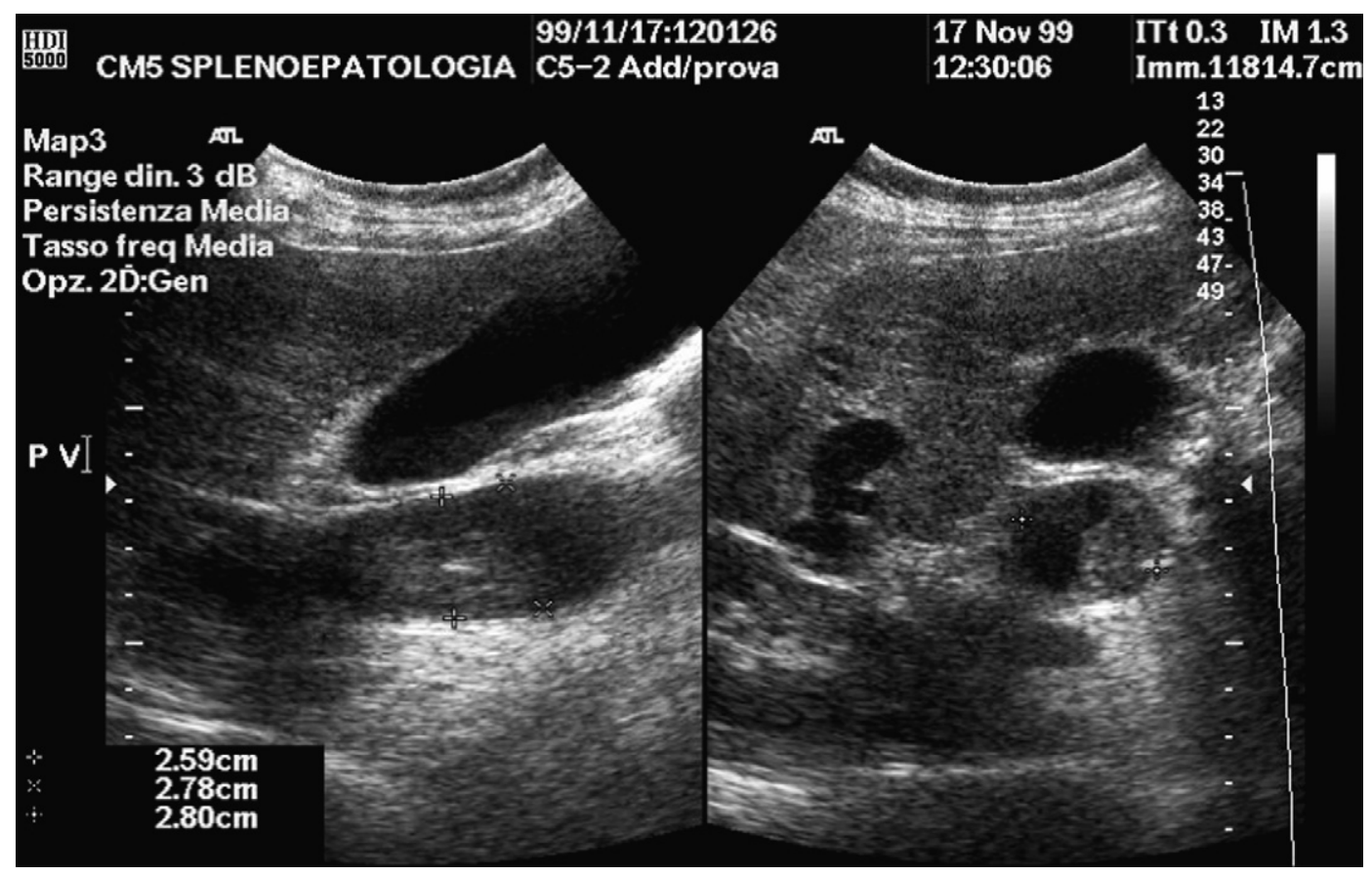

Fig. 1 Partial thrombosis of the portal vein. Echogenic material can be seen occluding the lumen of the portal vein by approximately $50 \%$.

Fig. 1 Trombosi parziale della vena porta. È visibile nella vena porta del materiale ecogeno che occlude circa metà del lume. 


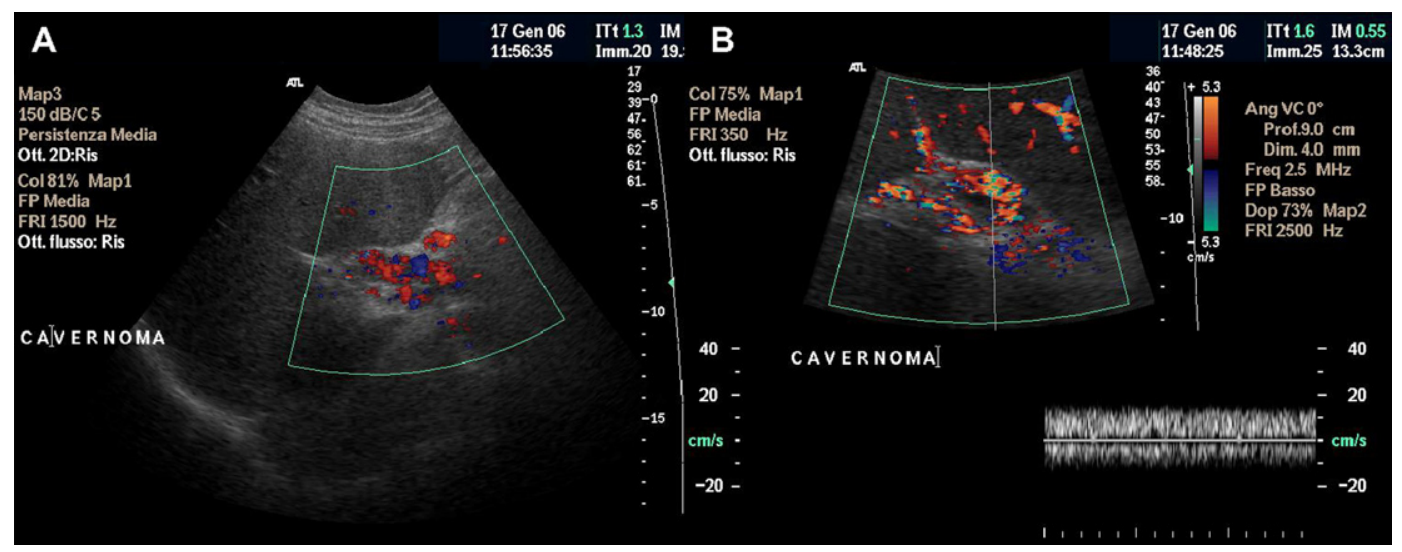

Fig. 2 Portal vein cavernoma.

Fig. 2 Cavernoma portale.

splenectomy, however, CT seems to be more accurate than color Doppler ultrasound [37]. Color Doppler can also demonstrate the presence of pulsatile flow within a neoplastic thrombus [38].

In our experience, indices of arterial resistance at the hepatic and splenic levels can also play an important role in the diagnosis of portal vein thrombosis. As noted above, portal vein thrombosis produces a buffer response that involves vasodilatation of the hepatic artery aimed at maintaining adequate hepatic perfusion. In the acute and subacute phases, this phenomenon can be documented with color Doppler as decreased hepatic artery resistance (Fig. 5) [39]. Since this vasodilatation does not occur when the liver is cirrhotic (Fig. 5) [40], the Doppler study can also provide

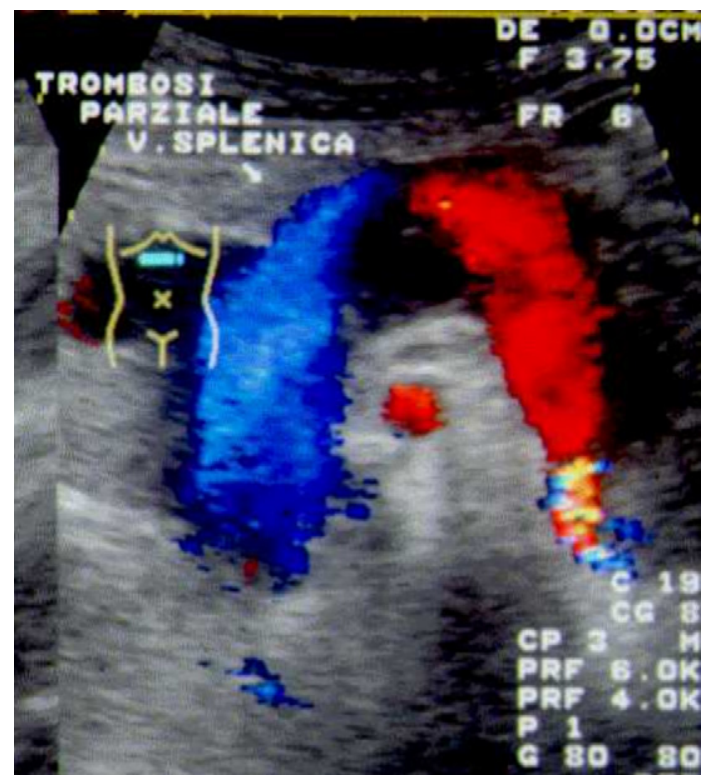

Fig. 3 Subtotal thrombosis of the retropancreatic segment of the splenic vein: Color Doppler reveals a flow defect and the presence of flow upstream to and downstream from the thrombus.

Fig. 3 Trombosi subtotale della vena splenica retropancreatica. Il color-Doppler dimostra il difetto di flusso e la sua presenza a monte e a valle. important information on the state of the liver itself (thus eliminating the need for liver biopsy, which is recommended by many authors for the diagnosis of cirrhosis). Regardless of whether or not cirrhosis is present, PVT is associated with increased arterial resistance indices at the splenic level as a result of the obstruction to splenic outflow [41].

Angio-MRI is similar to angiography in terms of sensitivity ( $100 \%$ vs. $91 \%$, respectively), specificity ( $98 \%$ vs. $100 \%)$, and accuracy (99\% vs. 96\%) [42], and it also provides important information on the involvement of biliary structures in collateral circuits. Some authors maintain that angiography is the method of choice for use in the postoperative evaluation of transplant patients, but it is by no means riskfree, especially in small children [43].

In patients without cirrhosis, there are indirect signs of portal hypertension such as splenomegaly, hypersplenism with low platelet and white-blood cell counts, and the presence of esophageal varices.

In patients with noncirrhotic extrahepatic PVT, findings suggestive of subclinical disseminated intravascular coagulation have been reported (increased prothrombin time, low platelet counts with hyperaggregability, low fibrinogen levels, and increased levels of fibrinogen-breakdown products) [44]. In patients with thrombotic involvement in the splanchnic district (even if there are known local risk factors, including cirrhosis), it is important to rule out the presence of unrecognized thrombophilic factors, especially undiagnosed myeloproliferative disease. To this end, bonemarrow biopsy with an endogenous erythroid colony (EEC) count should be performed. The EEC count is a sensitive indicator of latent or occult myeloproliferative disorders associated with thrombosis of the splanchnic vessels, and it is closely correlated with the results of the bone-marrow biopsy. The presence of a normal or elevated platelet count $\left(>200 \times 10^{9}\right)$ together with marked splenomegaly is suggestive of myeloproliferative disease. Histological findings of abnormal megakariocytopoiesis associated with the presence of EECs are indicative of myeloproliferative diseases that are likely to worsen [45].

Additional studies that are called for include a complete coagulation profile that includes genetic data: levels of proteins $\mathrm{C}$ and S, AT III; genetic anomalies involving factor $\mathrm{V}$ Leiden, MTHFR, factor VIII; assays for antiphospholipid antibodies and the lupus anticoagulant. 


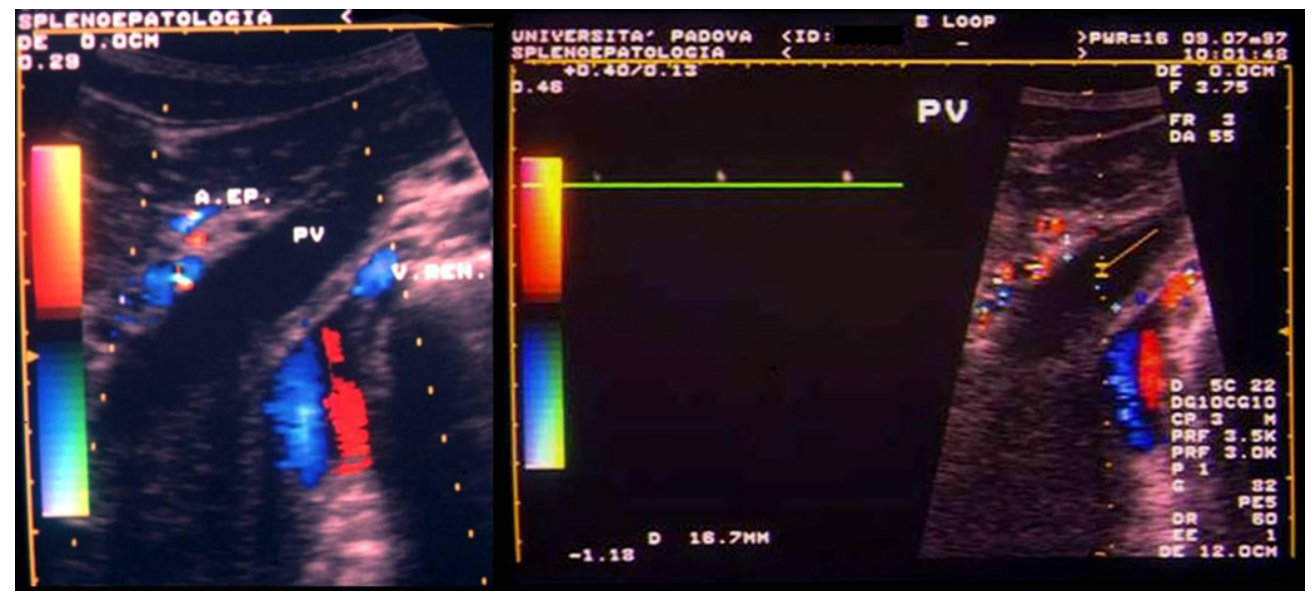

Fig. 4 Complete thrombosis of the portal vein. The thrombus itself cannot be visualized with sonography, but color Doppler reveals an absence of flow that is confirmed by pulsed Doppler findings.

Fig. 4 Trombosi completa della vena porta. Ecograficamente non è visualizzabile il trombo, ma vi è assenza di flusso al colorDoppler, confermata dal Doppler pulsato.

\section{Prognosis}

The prognosis for portal vein thrombosis has generally been studied in young subjects with neither cirrhosis nor neoplastic disease $[25,46]$ or in those diagnosed at much more advanced stages, compared with those identified today with modern diagnostic techniques. In addition, many of these studies were conducted before endoscopic treatment was available for bleeding esophageal varices [47]. Back then, variceal hemorrhages were one of the main causes of death in patients with portal vein thrombosis. Today, they are a much less common cause of mortality thanks to earlier diagnosis and endoscopic treatment. The most recent studies reveal one-, five-, and ten-year survival rates of $70 \%, 61 \%$, and $54 \%$, respectively, for patients with

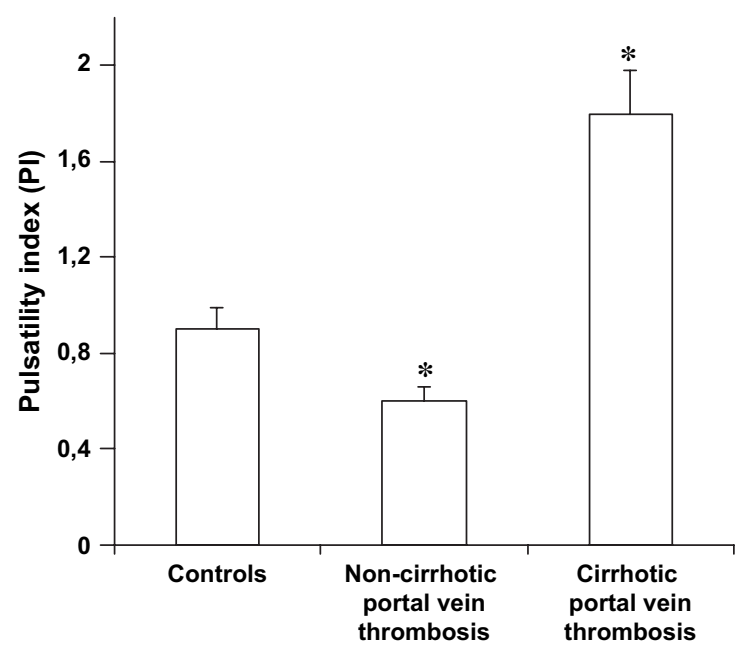

Fig. 5 Hepatic artery pulsatility indices (PI) in healthy subjects and patients with portal vein thrombosis (noncirrhotic and cirrhotic). ${ }^{*}=p<0.05$.

Fig. 5 Indice di pulsatilità $(\mathrm{PI})$ arteriosa epatica in soggetti sani e in pazienti con trombosi portale su fegato sano e su cirrosi. ${ }^{*}=p<0,05$. cirrhotic or noncirrhotic forms of PVT, and bleeding esophageal varices account for only $6 \%$ of the deaths. For patients with noncirrhotic, non-neoplastic PVT that does not involve the mesenteric vein, one-, five-, and ten-year survival rates are considerably higher $(95 \%, 89 \%$, and $81 \%$, respectively), and bleeding esophageal varices are the cause of death in only $2 \%$ of all cases [47].

The major risk factors in cases of PVT are the presence of neoplastic disease, cirrhosis, cardiopulmonary problems, and thrombosis of the mesenteric vein.

The prognosis for noncirrhotic PVT is better than that for cirrhotic forms with similar degrees of liver dysfunction and portal hypertension. The difference in terms of survival can probably be attributed to the progressive nature of cirrhosis. The patient with cirrhosis is more likely to experience complications related to increases in portal hypertension (with consequent increases in the presence of esophageal varices and the risk of bleeding). In noncirrhotic forms, the condition is not progressive, and as collaterals develop, varices may regress and eventually disappear [26].

In patients with HCC, the prognosis is worsened by the development of portal vein thrombosis. Some authors feel that it is also a contraindication for transarterial chemoembolization (TACE) (due to the risk of liver failure) [48], whereas others do not view it as a contraindication [49].

\section{Treatment}

\section{Noncirrhotic portal vein thrombosis}

As far as treatment is concerned, it is important to distinguish first of all between interventions aimed at resolving PVT itself and those used to treat the complications of PVT, particularly portal hypertension. With reference to the former, recent-onset thrombosis must be distinguished from more long-standing forms, including those characterized by portal cavernomas. For recent-onset cases, there is now evidence that anticoagulant therapy can be helpful although the issue has yet to be evaluated in an adequately 
large series of patients. With no treatment at all, recanalization is rare, but patency was restored in over $80 \%$ of all patients who were treated with anticoagulants [50]. Treatment should be continued for at least six months in patients with no known thrombogenic risk factors and those with risk factors, anticoagulation should be continued for life $[50,51]$. (Naturally, risk factors should be eliminated whenever possible, e.g., use of oral contraceptives.) The use of anticoagulants also seems to reduce the risk of complications, both early (intestinal ischemia) and late (portal hypertension), suggesting that they can play a major role in terms of prevention [51].

There is not enough data to allow reliable estimates of the risk-benefit indexes of more aggressive approaches based on systemic administration of thrombolytic agents, transjugular intrahepatic portosystemic shunts (TIPS) $[52,53]$, or surgical thrombectomy [54]. In patients with acute or subacute thrombosis of the portal vein and/or superior mesenteric vein, systemically administered thrombolytics have proved to be highly effective in reducing the high rate of hemorrhagic and infective complications [55].

In forms of PVT caused by infectious processes (pylephlebitis), antibiotics alone are usually sufficient, and recanalization can be achieved without anticoagulants [15].

The approach is less clear-cut when the patient has longstanding PVT and/or cavernomas. It has been shown that anticoagulation is effective in the prevention of re-thrombosis without increasing the risk for or the severity of bleeding [19]. Nonetheless, there is no real consensus on the use of anticoagulation. It may be an option in patients with documented persistent prothrombotic states [56]. It is important to recall that anticoagulant therapy should always be preceded by the elimination of all varices by means of ligation or sclerosis.

\section{Cirrhotic portal vein thrombosis}

Data on the treatment of cirrhotic forms of portal vein thrombosis are even more limited [56]. In patients on waiting lists for liver transplants, whose cirrhosis is in the advanced stages, a recent study has shown that anticoagulant therapy is followed by complete recanalization in $42 \%$ of all cases whereas no improvement at all is observed in the absence of such therapy [22]. Amitrano et al. maintain that anticoagulation should be considered for all cirrhotic patients with signs of intestinal ischemia or infarction, but the indications are less clear for use of anticoagulants to prevent variceal bleeding in patients with PVT who are awaiting liver transplants [23].

\section{Liver transplantation}

In the past, portal vein thrombosis was regarded as an absolute contraindication to liver transplantation, and its incidence among patients on transplant waiting lists was estimated at $8.4 \%$ [22]. This view has changed in many centers since no differences have been found between recipients with or without PVT in terms of either survival or transplanted organ function [57]. Thrombosis is considered a risk factor for increased morbidity and mortality $[57,58]$. Two-year survival rates are similar among recipients whose portal veins are partially thrombosed $(83 \%)$ or patent $(82 \%)$ at the time of transplant, but they are significantly lower (50\%) in those with complete thrombosis. Reported rates of recurrent thrombosis vary from $0 \%$ to $25 \%$ or even $30 \%$, depending on the extension and severity of the thrombosis, and when the transplantation is performed [58].

\section{Treatment of portal hypertension}

The efficacy of beta-blockers and/or nitrates in the treatment of thrombus-related portal hypertension has never been adequately evaluated in clinical trials, although most experts feel that beta-blocker therapy should be tried in most cases. Acute variceal bleeding can be controlled with ligation or sclerotherapy, but there are no data on [the efficacy of these procedures in] primary prevention.

In conclusion, in the absence of cirrhosis and/or hepatocellular carcinoma, portal vein thrombosis, mostly associated with multiple risk factors, is infrequent, but it should be considered in clinical practice since it is readily diagnosed by echo-color-Doppler. Early detection, also in cirrhosis, is fundamental because treatment with anticoagulants (and in some cases thrombolytics) can improve or even eliminate the thrombosis before it causes complications, e.g., intestinal necrosis and, chronically, bleeding caused by the rupture of gastro-esophageal varices. Although these hemorrhages are generally less severe in non-cirrhotic patients than in cirrhotic portal hypertension, they are nonetheless associated with moderately high mortality rates. Portal vein thrombosis in cirrhotic patients, although increasing morbidity and mortality, cannot be considered an absolute contraindication to liver transplantation. The search for prothrombotic disorders is useful for possible specific treatment and for prevention in relatives.

\section{References}

[1] Lautt WW. Mechanism and role of intrinsic regulation of hepatic arterial blood flow: the hepatic buffer response. Am J Physiol 1985;249:G549-56.

[2] Gerunda GE, Bolognesi M, Neri D, et al. Preoperative selective portal vein embolization [PSPVE] before major hepatic resection. Effectiveness of Doppler estimation of hepatic blood flow to predict the hypertrophy rate of non-embolized liver segments. Hepatogastroenterology 2002;49:1405-11.

[3] Ogren $M$, Bergqvist $D$, Bjorck $M$, Acosta $S$, Eriksson $H$, Sternby NH. Portal vein thrombosis: prevalence, patient characteristics and lifetime risk: a population study based on 23,796 consecutive autopsies. World J Gastroenterol 2006;12:2115-9.

[4] Denninger MH, Chait $\mathrm{Y}$, Casadevall N, et al. Cause of portal or hepatic venous thrombosis in adults: the role of multiple concurrent factors. Hepatology 2000;31:587-91.

[5] Primignani M, Martinelli I, Bucciarelli P, et al. Risk factors for thrombophilia in extrahepatic portal vein obstruction. Hepatology 2005;41:603-8.

[6] Bertina RM, Koeleman BP, Koster T, et al. Mutation in blood coagulation factor $\mathrm{V}$ associated with resistance to activated protein C. Nature 1994;369:64-7.

[7] Zoller B, Holm J, Svensson P, Dahlback B. Elevated levels of prothrombin activation fragment $1+2$ in plasma from patients with heterozygous Arg506 to Gln mutation in the 
factor $\mathrm{V}$ gene [APC-resistance] and/or inherited protein $\mathrm{S}$ deficiency. Thromb Haemost 1996;75:270-4.

[8] Mahmoud AE, Elias E, Beauchamp N, Wilde JT. Prevalence of the factor $V$ Leiden mutation in hepatic and portal vein thrombosis. Gut 1997;40:798-800.

[9] den Heijer M, Rosendaal FR, Blom HJ, Gerrits WB, Bos GM. Hyperhomocysteinemia and venous thrombosis: a meta-analysis. Thromb Haemost 1998;80:874-7.

[10] Godeau B, Leroy-Matheron C, Gouault-Heilmann M, Schaeffer A. A case of portal vein thrombosis associated with protein $S$ deficiency. J Hepatol 1993;18:258.

[11] Prignet JM, Duval JL, Raynard B, et al. Portal vein thrombosis and rupture of the esophagus secondary to a barotrauma. Gastroenterol Clin Biol 1996;20:103-5.

[12] Zigrossi P, Campanini M, Bordin G, et al. Portal and mesenteric thrombosis in protein S [pS] deficiency. Am J Gastroenterol 1996;91:163-5.

[13] Condat B, Pessione F, Hillaire S, et al. Current outcome of portal vein thrombosis in adults: risk and benefit of anticoagulant therapy. Gastroenterology 2001;120:490-7.

[14] Valla D, Casadevall N, Huisse MG, et al. Etiology of portal vein thrombosis in adults. A prospective evaluation of primary myeloproliferative disorders. Gastroenterology 1988;94: 1063-9.

[15] Trum JW, Valla D, Cohen G, Degott C, Rueff B, Santoni P. Bacteroides bacteremia of undetermined origin: strong association with portal vein thrombosis and cryptogenic pylephlebitis. Eur J Gastroenterol Hepatol 1993;5:655-9.

[16] Talbot RW, Heppell J, Dozois RR, Beart Jr RW. Vascular complications of inflammatory bowel disease. Mayo Clin Proc 1986;61:140-5.

[17] Neidballa RG. A large spontaneous portacaval shunt. Arch Intern Med 1966;117:54-6.

[18] Bernades P, Baetz A, Levy P, Belghiti J, Menu Y, Fekete F. Splenic and portal venous obstruction in chronic pancreatitis. A prospective longitudinal study of a medical-surgical series of 266 patients. Dig Dis Sci 1992;37:340-6.

[19] Francoz C, Belghiti J, Vilgrain V, et al. Splanchnic vein thrombosis in candidates for liver transplantation: usefulness of screening and anticoagulation. Gut 2005;54:691-7.

[20] Ruol A, Finucci GF, Sacerdoti D. Le trombosi venose del distretto circolatorio portale. Medicina Clinica. Diagnostica e terapia 1993;7:775-92.

[21] Erkan O, Bozday AM, Disibeyaz S, et al. Thrombophilic gene mutations in cirrhotic patients with portal vein thrombosis. Eur J Gastroenterol Hepatol 2005;17:339-43.

[22] Mangia A, Villani MR, Cappucci G, et al. Causes of portal venous thrombosis in cirrhotic patients: the role of genetic and acquired factors. Eur J Gastroenterol Hepatol 2005;17:745-51.

[23] Amitrano L, Guardascione MA, Brancaccio V, et al. Risk factors and clinical presentation of portal vein thrombosis in patients with liver cirrhosis. J Hepatol 2004;40:736-41.

[24] Fimognari FL, De Santis A, Piccheri C, et al. Evaluation of D-dimer and factor VIII in cirrhotic patients with asymptomatic portal venous thrombosis. J Lab Clin Med 2005;146:238-43.

[25] Webb LJ, Sherlock S. The aetiology, presentation and natural history of extra-hepatic portal venous obstruction. Q J Med 1979;48:627-39.

[26] Merkel C, Bolognesi M, Bellon S, et al. A long-term follow-up study of adult patients with non-cirrhotic obstruction of the portal system: comparison with cirrhotic patients. J Hepatol 1992;15:299-303.

[27] Webster GJ, Burroughs AK, Riordan SM. Review article: portal vein thrombosis - new insights into aetiology and management. Aliment Pharmacol Ther 2005;21:1-9.

[28] Hagimoto T, Seo $M$, Okada $M$, et al. Portal vein thrombosis successfully treated with a colectomy in active ulcerative colitis: report of a case. Dis Colon Rectum 2001;44:587-90.
[29] Maddrey WC, Boyer JL, Sen NN, Thomas J, Basu AK, Iber FL. Plasma volume expansion in portal hypertension. John Hopkins Med J 1969;125:171-83.

[30] De Franchis R, Primignani M. Natural history of portal hypertension in patients with cirrhosis. Clin Liver Dis 2001;5: 645-63.

[31] Nonami T, Yokoyama I, Iwatsuki S, Starzl TE. The incidence of portal vein thrombosis at liver transplantation. Hepatology 1992;6:1195-8.

[32] Jamieson NV. Changing perspectives in portal vein thrombosis and liver transplantation. Transplantation 2000;15(69): 1772-4.

[33] Miller VE, Berland LL. Pulsed Doppler duplex sonography and CT of portal vein thrombosis. AJR Am J Roentgenol 1985; 145:73-6.

[34] Scoutt LM, Zawin ML, Taylor KJ. Doppler US. Part II. Clinical applications. Radiology 1990;174:309-19.

[35] Marshall MM, Beese RC, Muiesan P, Sarma DI, O'Grady J, Sidhu PS. Assessment of portal venous system patency in the liver transplant candidate: a prospective study comparing ultrasound, microbubble-enhanced colour Doppler ultrasound, with arteriography and surgery. Clin Radiol 2002;57: 377-83.

[36] Bach AM, Hann LE, Brown KT, et al. Portal vein evaluation with US: comparison to angiography combined with CT arterial portography. Radiology 1996;201:149-54.

[37] Chaffanjon PC, Brichon PY, Ranchoup Y, Gressin R, Sotto JJ. Portal vein thrombosis following splenectomy for hematologic disease: prospective study with Doppler color flow imaging. World J Surg 1998;22:1082-6.

[38] Ricci P, Cantisani V, Biancari F, et al. Contrast-enhanced color Doppler US in malignant portal vein thrombosis. Acta Radiol 2000;41:470-3.

[39] Sacerdoti D, Bolognesi M, Bombonato GC, Merkel C, Gatta A. Pathophysiology of arterial Doppler parameters in portal hypertension. Ultrasound Med Biol 2000;26(Suppl. B):A120.

[40] Sacerdoti D, Merkel C, Bolognesi M, Amodio P, Angeli P, Gatta A. Hepatic arterial resistance in cirrhosis with and without portal vein thrombosis: relationships with portal hemodynamics. Gastroenterology 1995;108:1152-8.

[41] Bolognesi M, Sacerdoti D, Merkel C, et al. Splenic Doppler impedance indices: influence of different portal hemodynamic conditions. Hepatology 1996;23:1035-40.

[42] Kreft B, Strunk H, Flacke S, Wolff M, et al. Detection of thrombosis in the portal venous system: comparison of contrastenhanced $M R$ angiography with intraarterial digital subtraction angiography. Radiology 2000;216:86-92.

[43] Cheng YF, Chen CL, Huang TL, et al. Risk factors for intraoperative portal vein thrombosis in pediatric living donor liver transplantation. Clin Transpl 2004;18:390-4.

[44] Bajaj JS, Bhattacharjee J, Sarin SK. Coagulation profile and platelet function in patients with portal extrahepatic portal vein obstruction and non-cirrhotic portal fibrosis. J Gastroenterol Hepatol 2001;16:595-6.

[45] Chait Y, Condat B, Cazals-Hatem D, et al. Relevance of the criteria commonly used to diagnose myeloproliferative disorder in patients with splanchnic vein thrombosis. $\mathrm{Br} \mathrm{J}$ Haematol 2005;129:553-60.

[46] Fonkalsrud EW, Myers NA, Robinson MJ. Management of extrahepatic portal hypertension in children. Ann Surg 1974;180: 487-93.

[47] Janssen HL, Wijnhoud A, Haagsma EB, et al. Extrahepatic portal vein thrombosis: aetiology and determinants of survival. Gut 2001;49:720-4.

[48] Cheong JY, Lee KM, Cho SW, et al. Survival benefits of intraarterial infusion chemotherapy in patients with advanced hepatocellular carcinoma with portal vein tumor thrombosis. Hepatol Res 2005;32:127-33. 
[49] Georgiades CS, Hong K, D’Angelo M, Geschwind JF. Safety and efficacy of transarterial chemoembolization in patients with unresectable hepatocellular carcinoma and portal vein thrombosis. J Vasc Interv Radiol 2005;16:1653-9.

[50] Baril N, Wren S, Radin R, Ralls P, Stain S. The role of anticoagulation in pylephlebitis. Am J Surg 1996;172:449-52.

[51] Condat B, Pessione F, Helene Denninger M, Hillaire S, Valla D. Recent portal or mesenteric venous thrombosis: increased recognition and frequent recanalization on anticoagulant therapy. Hepatology 2000;32:466-70.

[52] Blum U, Haag K, Rossle $M$, et al. Noncavernomatous portal vein thrombosis in hepatic cirrhosis: treatment with transjugular intrahepatic portosystemic shunt and local thrombolysis. Radiology 1995;195:153-7.

[53] Senzolo M, Tibbals J, Cholongitas E, Triantos CK, Burroughs AK, Patch D. Transjugular intrahepatic portosystemic shunt for portal vein thrombosis with and without cavernous transformation. Aliment Pharmacol Ther 2006;23: 767-75.
[54] Klempnauer J, Grothues F, Bektas H, Pichlmayr R. Results of portal thrombectomy and splanchnic thrombolysis for the surgical management of acute mesentericoportal thrombosis. $\mathrm{Br}$ J Surg 1997;84:129-32.

[55] Hollingshead M, Burke CT, Mauro MA, Weeks SM, Dixon RG, Jaques PF. Transcatheter thrombolytic therapy for acute mesenteric and portal vein thrombosis. J Vasc Interv Radiol 2005; 16:651-61.

[56] De Franchis R. Evolving consensus in portal hypertension. Report of the Baveno IV consensus workshop on methodology of diagnosis and therapy in portal hypertension. J Hepatol 2005;43:167-76.

[57] Charco R, Fuster J, Fondevila C, Ferrer J, Mans E, GarciaValdecasas JC. Portal vein thrombosis in liver transplantation. Transplant Proc 2005;37:3904-5.

[58] Gimeno FA, Calvo J, Loinaz C, et al. Comparative analysis of the results of orthotopic liver transplantation in patients with and without portal vein thrombosis. Transplant Proc 2005;37:3899-903. 